\title{
A model for prediction of overtopping at berm breakwaters
}

\author{
$\underline{\text { Amir Etemad-Shahidi }}{ }^{\text {a }}$ and Ebrahim Jafari ${ }^{\text {b }}$ \\ ${ }^{a}$ Griffith School of Engineering, Gold Coast Campus, Griffith University, QLD 4222, Australia \\ ${ }^{b}$ School of Civil Engineering, Faculty of Engineering, University of Tehran, Iran \\ Email: a.etemadshahidi@griffith.edu.au
}

\begin{abstract}
Reliable prediction of wave overtopping rate is a key task in the design and safety assessment of coastal structures. The overtopping rates must be lower than the allowable rate both in normal operating and extreme conditions to guarantee the safety of both people and assets on and behind the breakwaters. The sea level rise caused by climate change and its effects on wave climate enhance the overtopping rate and make the existing coastal structures more vulnerable to the overtopping.

In the past decades, several approaches have been developed for prediction of overtopping rate in different structures, including empirical formulae, numerical models, and soft-computing methods. The most commonly used models are empirical ones. Typically, these models are developed by fitting dimensionless parameters to experimental data obtained from physical model tests. The most popular empirical formulae proposed for berm breakwaters are the formulae of Van der Meer and Janssen (1995) and EurOtop (Pullen et al. 2007). However, the applicability of these formulae is limited to specific structures and wave conditions for which the models were developed. Hence, a more comprehensive dataset which includes multiple tests with different structural and hydraulic conditions would enhance the robustness and reliability of the developed models.
\end{abstract}

As a part of the European CLASH project framework, two different ANN models for various types of coastal structures are developed. These models can also be used for the prediction of wave overtopping rate at rubble mound breakwaters with berms. However, using ANN models may not always be desirable, because, they have complicated structures and are not as transparent and understandable as empirical models. On the other hand, practical applications of these models need engineers to have some data mining knowledge which is not always the case.

In this study, a new formula for the prediction of wave overtopping rate at non-reshaping berm breakwaters is presented. In order to derive the new formula, extracted experimental data from the CLASH database is implemented and the effects of the most important governing parameters are considered. Several models were developed using various dimensionless parameters that seemed to be influential and the model which outperformed the other ones was selected. The final model considers the effects of dimensionless crest freeboard, dimensionless crest width and average angle of the structure slopes. The new formula's performance is then compared with those of previous empirical ones for prediction of overtopping rate. Statistical indicators such as Root Mean Square Error, RMSE show that the new formula outperforms the previous empirical ones.

Keywords: $\quad$ Non-reshaping berm breakwater, wave overtopping, CLASH database 


\section{INTRODUCTION}

Safety of the harbor basin and facilities protected by the breakwaters is mostly measured by the amount of water transmitted to the lee side of the structure; called "wave overtopping rate". Excessive wave overtopping rate can harm people and cause economical damage. It is harmful to people, vehicles and properties on or close to the breakwaters, as well as ships and boats inside the port basins. Therefore, a reliable prediction of wave overtopping rate can reduce the potential risk in the design of coastal protection structures.

Several approaches have been developed for prediction of overtopping rate in recent decades, including empirical formulae (e.g. Van der Meer and Janssen 1995), Artificial Neural Networks or ANN (e.g. Van Gent et al. 2007, Verhaeghe et al. 2008) models, and model tree approaches (e.g. Jafari and Etemad-Shahidi 2012, Etemad-Shahidi and Jafari 2014). The first and still most commonly used models are empirical ones. Typically, these models are developed by fitting dimensionless parameters to experimental data obtained from physical model tests. The most popular empirical formulae proposed for rubble mound structures with berms are the formulae of Van der Meer and Janssen (1995) and EurOtop (Pullen et al. 2007). The range of validation of these formulae is limited to specific structures and wave conditions for which the models were developed (Neves et al. 2008). Hence, if there is a more comprehensive dataset which includes multiple tests with different structural and hydraulic conditions, the developed model using that dataset would be more reliable and robust.

The interest in soft-computing methods such as artificial neural networks to the prediction of wave overtopping rate has grown in the past decade. As a part of the European CLASH project framework (De Rouck et al. 2009), Van Gent et al. (2007) and Verhaeghe et al. (2008) proposed two different ANN models for various types of coastal structures. These models can also be applied for prediction of wave overtopping rate at rubble mound breakwaters with berms. However, using ANN models may not always be the best choice. This is mainly due to the fact that they have complicated structures and are not as transparent and do not provide insight in the process as empirical models. On the other hand, coastal engineers are sometimes reluctant to use these models mainly because of lack of data mining knowledge.

The aim of this study is to develop a new formula for the prediction of wave overtopping rate at nonreshaping rubble mound breakwaters with berms. The formula was developed by using scaling argument and fitting dimensionless parameters to the experimental data extracted from the CLASH database. The predicted overtopping rates, applying the new formula, are then compared with those of the previous empirical ones.

\section{SELECTION OF DATA FROM THE CLASH DATABASE}

The data used in this study was extracted from the CLASH database (De Rouck et al. 2009). Within the CLASH project, an extensive database on wave overtopping was created, consisting of many laboratory tests and a few prototype overtopping measurements. The database includes data resulting from different experiments performed at several institutions and laboratories at different scales, using various measurement tools and different precision. More information about the database and experiments can be found in Verhaeghe (2005) and Van der Meer et al. (2009).

The data of wave overtopping at non-reshaping rubble mound structures with berms were selected in this study. To extract the data of the rubble mound breakwaters, tests with sloped rough surface were selected. In the CLASH database, a complexity factor $C F$ is assigned to each structure and a reliability factor $R F$ is assigned to each test. The $C F$ range varies from $C F=1$ for a very simple structure to $C F=4$ for a very complex structure. On the other hand, $R F=1$ refers to a very reliable test, while $R F=4$ refers to a non-reliable test (Van Gent et al. 2007). Here, in order to have a reliable and accurate database, the data with $C F=4$ and $R F=4$ have been excluded from further processing. In addition, to reduce the crown wall effects, the tests with wave-walls on the top of the structure have been left out. Due to the measurement errors, very low overtopping discharges in small scale tests may not be accurate. Hence, only 109 head-on wave tests with the values of $q \geq 1 \times 10^{-6} \mathrm{~m}^{3} / \mathrm{s} / \mathrm{m}$ were used for development of the new formula.

\section{RESULTS OF PREVIOUS EMPIRICAL FORMULAE}

As mentioned before, empirical formulae have been developed for prediction of overtopping rate of rubble mound structures with berms. The most commonly used ones are the formulae of Van der Meer and Janssen (1995) and EurOtop (Pullen et al. 2007). Van der Meer and Janssen (1995) presented the following formulae for impermeable core sloping structures: 
Etemad-Shahidi and Jafari, Derivation of a new model for prediction of wave overtopping at berm breakwaters

$$
\begin{aligned}
& \text { if } \xi_{o p}<2 \rightarrow \frac{q}{\sqrt{g \cdot H_{S}^{3}}} \sqrt{\frac{s_{o p}}{\tan \alpha}}=0.06 \cdot \exp \left(-5.2 \frac{R_{C}}{H_{S}} \frac{\sqrt{s_{o p}}}{\tan \alpha} \frac{1}{\gamma_{f} \cdot \gamma_{b} \cdot \gamma_{h} \cdot \gamma_{\beta}}\right) \\
& \text { if } \xi_{o p}>2 \rightarrow \frac{q}{\sqrt{g \cdot H_{S}^{3}}}=0.2 \cdot \exp \left(-2.6 \frac{R_{C}}{H_{S}} \frac{1}{\gamma_{f} \cdot \gamma_{b} \cdot \gamma_{h} \cdot \gamma_{\beta}}\right)
\end{aligned}
$$

where $q$ is the mean overtopping discharge, $H_{S}$ is the significant wave height, $R_{C}$ is the crest freeboard, $\alpha$ is the slope angle and $g$ is the gravitational accelerator. $\xi_{o p}$ is the surf similarity parameter (Iribarren number) and $S_{o p}$ is the deep water wave steepness defined as:

$$
\begin{aligned}
& \xi_{o p}=\frac{\tan \alpha}{\sqrt{S_{o p}}} \\
& S_{o p}=\frac{H_{S}}{L_{o p}}=\frac{2 \pi}{g} \frac{H_{S}}{T_{P}{ }^{2}}
\end{aligned}
$$

where $L_{o p}$ is the deep water wave length and $T_{p}$ is the period related to the peak of the wave spectra. The reduction factors in eq. (1) and eq. (2) include the surface roughness $\gamma_{f}(<1$ for rough slopes), the berm effect $\gamma_{b}\left(\gamma_{b}<1\right.$ for bermed profiles), the influence of shallow- water conditions $\gamma_{h}$ (=1 for Rayleigh distributed waves), and the effect of wave obliquity $\beta, \gamma_{\beta}$ (=1 for head-on waves). The reduction factor of berm effect $\gamma_{b}$ is defined as (Figure 1):

$$
\gamma_{b}=\frac{\xi_{e q}}{\xi_{o p}}=1-r_{B}\left(1-r_{d B}\right), \quad 0.6 \leq \gamma_{b} \leq 1.0
$$

where:

$$
\begin{aligned}
& r_{B}=1-\frac{\tan \alpha_{e q}}{\tan \alpha} \\
& r_{d B}=0.5\left(\frac{d_{B}}{H_{s}}\right)^{2}, \quad 0 \leq r_{d B} \leq 1
\end{aligned}
$$

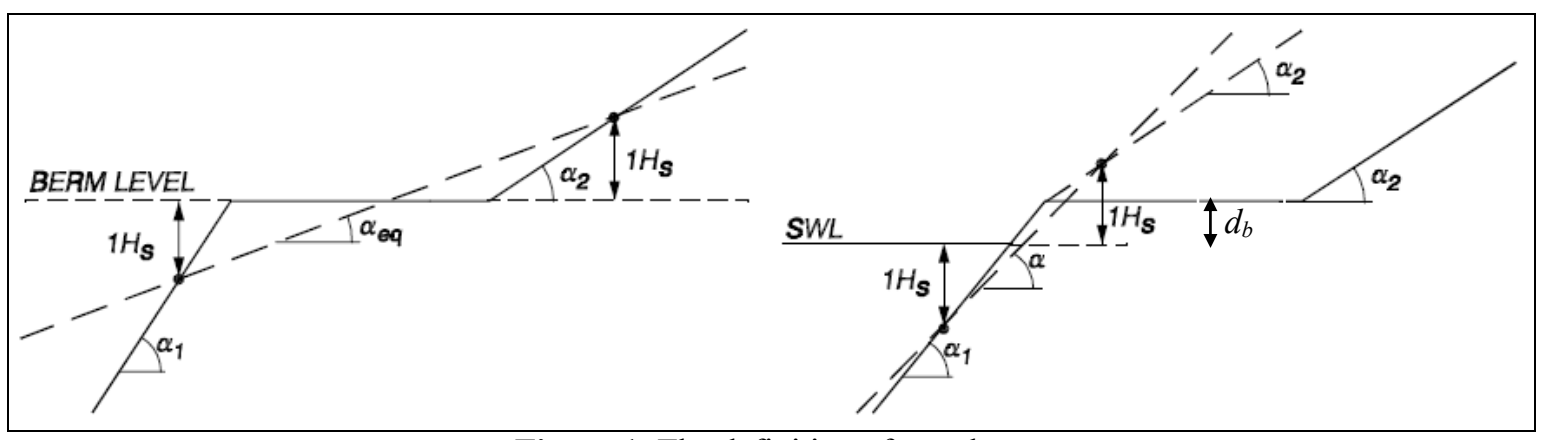

Figure 1. The definition of $\alpha$ and $\alpha_{\mathrm{eq}}$

Comparison between the measured and predicted overtopping rates for the extracted data from CLASH database is shown in the Figure 2. In the figure, $q^{*}$ is the dimensionless overtopping discharge defined as:

$$
q^{*}=\frac{q}{\sqrt{g \cdot H_{s}^{3}}}
$$

It is clear from the figure that there are significant scatters between the measured and the predicted overtopping rates; especially at low rates in where the predictions are several orders of magnitude underestimated. This may cause under-design of structural crest level and high risk of excessive overtopping. Figure 2 also shows the high level of uncertainty in Van der Meer and Janssen (1995) formulae for berm breakwaters. 
Etemad-Shahidi and Jafari, Derivation of a new model for prediction of wave overtopping at berm breakwaters

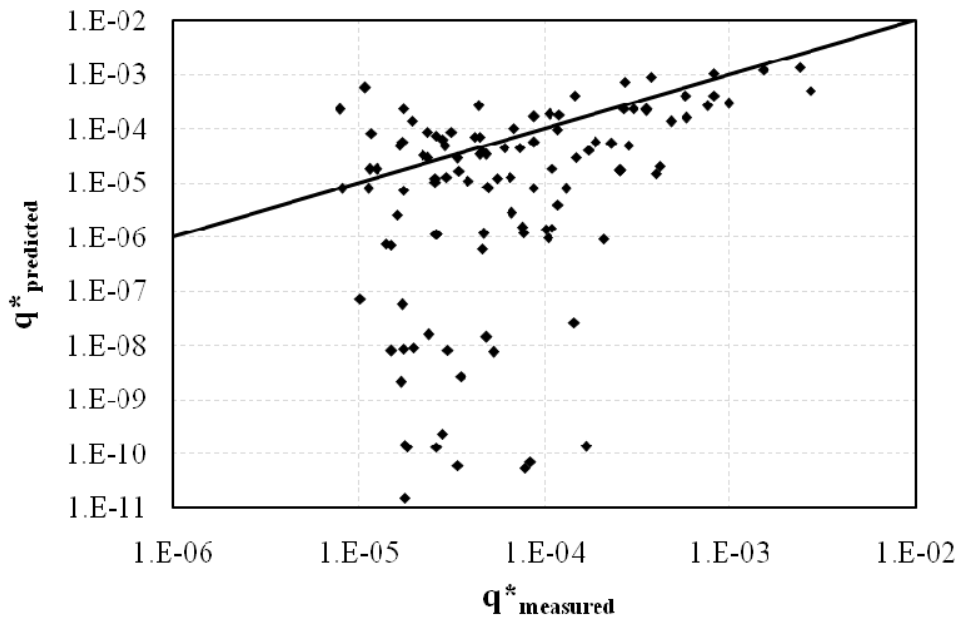

Figure 2. Comparison of the measured overtopping rate and the predicted ones using Van der Meer and Janssen (1995) formulae

The EurOtop manual (Pullen et al. 2007) suggests that for the prediction of wave overtopping at berm breakwaters, the single well-known formula of simple slope rubble mound breakwaters can be used (eq. 9). The only required modification is that the surface roughness reduction factor $\gamma_{f}$ should be considered equal to 0.35 (to include both the effects of berm and roughness) for non-reshaping berm breakwaters:

$$
\frac{q}{\sqrt{g \cdot H_{s}^{3}}}=0.2 \cdot \exp \left(-2.6 \frac{R_{C}}{H_{s} \cdot \gamma_{f} \cdot \gamma_{\beta}}\right)
$$

Comparison between the measured overtopping rates and the predicted ones using eq. (9) is shown in the Figure 3. This figure shows that although the predictions of EurOtop formula are less scattered than those of Van der Meer and Janssen formulae, there is still a large uncertainty in the predictions.

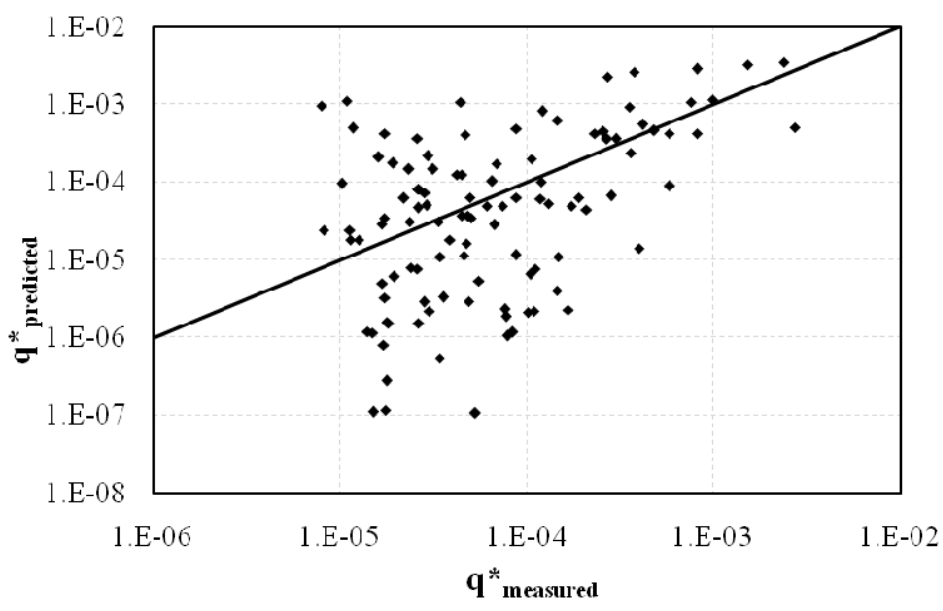

Figure 3. Comparison of the measured overtopping rate and the predicted ones using EurOtop (Pullen et al. 2007) formula

\section{MODELING AND RESULTS}

In this study, nonlinear multivariate regression was applied to develop a new formula using experimental data. Regression analysis is a conventional and well-known method for processing of the datasets. It includes many techniques for modeling and analyzing of several variables in the form of independent and dependent variables. The focus of this study was to use the most appropriate variables. Many techniques for carrying out regression analysis have been developed. In the most commonly used methods such as linear regression, dependent variables are presented as a linear function of independent variables plus an error value. In linear regression analysis, the optimum coefficients (of governing variables) are optimized in order to minimize the error in predictions. To develop the new model, parameters which seemed to be the most influential ones in the overtopping process were selected as independent variables. These variables include dimensionless crest 
Etemad-Shahidi and Jafari, Derivation of a new model for prediction of wave overtopping at berm breakwaters

freeboard, dimensionless crest width and average angle of the surface slopes. Using scaling arguments and considering the physics of the process, several models were developed using various dimensionless parameters that seemed to be important in the overtopping. Finally, a model which outperformed other ones was selected. Table 1 shows the final independent and dependent variables used for development of the new formula.

Table 1. The final independent and dependent variables used for development of the new formula.

\begin{tabular}{cc}
\hline independent variables & dependent variable \\
\hline$\frac{R_{C}}{H_{S} \cdot \gamma_{f}}, \frac{G_{C}}{H_{S}}, \tan \alpha_{\text {ave }}$ & $\frac{q}{\sqrt{g \cdot H_{S}^{3}}}$ \\
\hline
\end{tabular}

where $G_{c}$ is the dimensionless crest width. The dimensionless crest freeboard is the same as the one used in the EurOtop (Pullen et al. 2007) formula. The used $\gamma_{f}$ values are the same as those suggested for non-bermed breakwaters which represent the effects of surface roughness and permeability. The $\gamma_{f}$ values for different armor types and layers and permeabilities for non-bermed breakwaters are presented in Table 2 (Pullen et al. 2007).

Table 2. The reduction factor values for the effects of surface roughness and permeability on non-bermed breakwaters overtopping

\begin{tabular}{ll}
\hline Type of slop surface & $\gamma_{f}$ \\
\hline Smooth impermeable surface & 1.00 \\
\hline Rocks (1 layer, impermeable core) & 0.60 \\
\hline Rocks (1 layer, permeable core) & 0.45 \\
\hline Rocks (2 layers, impermeable core) & 0.55 \\
\hline Rocks (2 layers, permeable core) & 0.40 \\
\hline Cubes (1 layer, random positioning) & 0.50 \\
\hline Cubes (2 layers, random positioning) & 0.47 \\
\hline Antifers & 0.47 \\
\hline HARO's & 0.47 \\
\hline Accropode ${ }^{\mathrm{TM}}$ & 0.46 \\
\hline Xbloc ${ }^{\circledR}$ & 0.45 \\
\hline CORE-LOC® & 0.44 \\
\hline Tetrapods & 0.38 \\
\hline Dolosse & 0.43 \\
\hline
\end{tabular}

The "tan $\alpha_{\text {avg }}$ " in Table 1 represents the tangent of the average angle of the surface slopes. This parameter (see Figure 4) is defined as:

$$
\tan \alpha_{\text {ave }}=\frac{3 H_{S}}{L_{\text {Slope }}-B}=\frac{3 H_{S}}{\left(\left(1.5 H_{S}-d_{B}\right) \cot \alpha_{u}+\left(1.5 H_{S}+d_{B}\right) \cot \alpha_{d}\right)}
$$

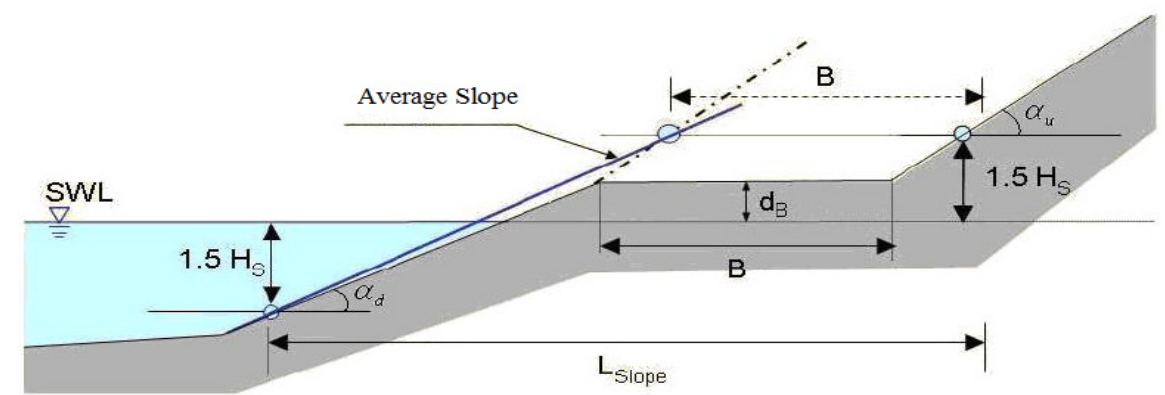

Figure 4. Definition of the average angle of the surface slopes (Pullen et al. 2007) 
Some of the previous empirical formulae for the prediction of wave overtopping rate such as those of Van der Meer and Janssen (1995) and EurOtop (Pullen et al. 2007) have an exponential form. Therefore, the exponential form was used for developing the new model and the optimum formula was elected as:

$$
\frac{q}{\sqrt{g \cdot H_{S}{ }^{3}}}=\exp \left(-0.97 \frac{R_{c}}{H_{s} \cdot \gamma_{f}}-0.4 \frac{G_{c}}{H_{s}}-1.04 \tan \alpha_{\text {ave }}-4.975\right)
$$

This formula is simple and transparent, as the previous empirical approaches. A scatter diagram of the measured and predicted dimensionless overtopping discharges by eq. (12) is shown in Figure 5. It is clear from the figure that the data points are more concentrated around the optimal line $(1: 1)$ compared to the previous formulae (Figures 2 and 3).

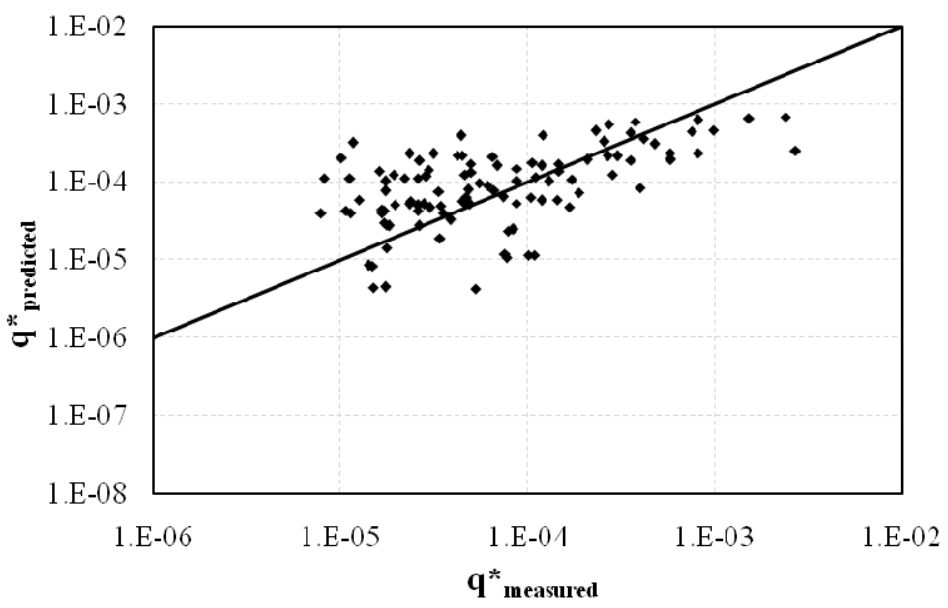

Figure 5. Comparison of the measured and the predicted overtopping rate using the new formula

To quantitatively evaluate the performance of the models, accuracy metrics such as $R^{2}$, geometric mean $\left(x_{G}\right)$, geometric standard deviation $\left(\sigma_{X G}\right)$, Bias and root mean square error $(R M S E)$ were determined:

$$
\begin{aligned}
& x_{G}=\exp \left(\frac{1}{n} \sum_{i=1}^{n} \ln \left(\frac{q_{\text {est }}^{*}}{q_{\text {meas }}^{*}}\right)\right) \\
& \sigma_{X G}=\exp \left(\sqrt{\frac{1}{n} \sum_{i=1}^{n}\left(\left(\ln \left(\frac{q_{\text {est }}^{*}}{q_{\text {meas }}^{*}}\right)\right)^{2}-\left(\ln \left(x_{G}\right)\right)^{2}\right)}\right) \\
& \text { Bias }=\frac{1}{n} \sum_{i=1}^{n}\left(\log q_{\text {est }}^{*}-\log q_{\text {meas }}^{*}\right) \\
& \text { RMSE }=\sqrt{\frac{1}{n} \sum_{i=1}^{n}\left(\log q_{\text {meas }}^{*}-\log q_{\text {est }}^{*}\right)^{2}}
\end{aligned}
$$

Where $q^{*}$ est and $q^{*}$ meas are the dimensionless estimated and measured overtopping rates, respectively and $n$ is the number of the measurements. Table 3 shows the accuracy metrics of the previous empirical formulae and of eq. (11). As shown, all of the metrics of the new model show improvement in the prediction of overtopping discharges. The geometric mean values show that the predictions of the new formula are slightly overestimated, while those of Van der Meer and Janssen (1995) and EurOtop (Pullen et al. 2007) are underestimated. Geometric standard deviation evaluates the scatter of data. As already seen in figures 2, 3 and 5, the values of $\sigma_{X G}$ in Table 3 also indicate that the estimations by the new formula are less scattered than those of others. Bias and RMSE errors also show that eq. (12) is more accurate than the other formulae. 
Etemad-Shahidi and Jafari, Derivation of a new model for prediction of wave overtopping at berm breakwaters

Table 3. Accuracy metrics of different formulae.

\begin{tabular}{lccc} 
& Van der Meer and Janssen & EurOtop & Eq. (11) \\
\hline $\boldsymbol{X}_{\boldsymbol{G}}$ & 0.07 & 0.60 & 1.36 \\
\hline $\boldsymbol{\sigma}_{\boldsymbol{x}}$ & 63.11 & 8.70 & 3.30 \\
\hline $\boldsymbol{R}^{\mathbf{2}}$ & 0.16 & 0.22 & 0.28 \\
\hline $\boldsymbol{B i a s}$ & -1.15 & -0.22 & 0.13 \\
\hline $\boldsymbol{R} \boldsymbol{M S E}$ & 2.14 & 0.97 & 0.53 \\
\hline
\end{tabular}

\section{SUMMARY AND CONCLUSIONS}

In this study, a new formula was presented for the prediction of the overtopping rate at non-reshaping berm breakwaters in head-on wave condition. The new formula was derived by applying scaling argument and dimensionless parameters to the extracted data from the CLASH database. Dimensionless crest freeboard and crest width of the structure and the tangent of the average angle of the surface slopes were used as the input independent parameters, while the output dependent variable was the dimensionless overtopping discharge. The performance of the model was evaluated using accuracy metrics and it was shown that the proposed formula is more accurate than the previous empirical formulae of Van der Meer and Janssen (1995) and the EurOtop (Pullen et al. 2007).

\section{ACKNOWLEDGEMENTS}

We acknowledge the EC-project CLASH organizer for providing their comprehensive and freely available database on the wave overtopping.

\section{REFERENCES}

De Rouck J., Verhaeghe H., and Geeraerts J. (2009). Crest level assessment of coastal structures - General overview, Coastal Engineering, 56(2), 99-107.

Etemad-Shahidi A. and Jafari E. (2014). New formulas for prediction of wave overtopping at inclined structures with smooth impermeable surface, Ocean Engineering, 84, 124-132

Jafari, E. and Etemad-Shahidi, A. (2012). Derivation of a new model for prediction of wave overtopping at rubble-mound structures. Journal of Waterway Port Coastal and Ocean Engineering-ASCE, 138, 42-52

Neves, M. G., Reis, M. T., Losada, I. J. and Hu, K. M. (2008). Wave overtopping of Povoa de Varzim breakwater: Physical and numerical simulations. Journal of Waterway Port Coastal and Ocean Engineering-ASCE, 134, 226-236.

Pullen, T., Allsop, N. W. H., Bruce, T., Kortenhaus, A., Schüttrumpf, H., and van den Meer, J. W. (2007). EurOtop wave overtopping of sea defenses and related structures-Assessment manual. UK Environment Agency, Netherlands Expertise Netwerk Waterkeren, and German Coastal Engineering Research Council, 181.

Van der Meer J.W. and Janssen W. (1995). Wave Run-Up and Wave Overtopping at Dikes, In Wave Forces on Inclined and Vertical Wall Structures, Kobayashi and Demirbilek, eds., American Society of Civil Engineers, 1-27.

Van der Meer J.W., Verhaeghe H., and Steendam G.J. (2009). The new wave overtopping database for coastal structures, Coastal Engineering, 56(2), 108-120.

Van Gent, M. R. A.,Van Den Boogaard, H. F. P.,Pozueta, B. and Medina, J. R. (2007). Neural network modelling of wave overtopping at coastal structures. Coastal Engineering, 54, 586-593.

Verhaeghe, H. (2005). Neural network prediction of wave overtopping at coastal structure. Doctorate Dissertation, Ghent University.

Verhaeghe, H., J. De Rouck, and J. van der Meer. (2008). Combined classifier-quantifier model: A 2-phases neural model for prediction of wave overtopping at coastal structures, Coastal Engineering, 55(5), 357374. 